Syntax Fusion: Jurnal Nasional Indonesia

e-ISSN: 2775-4440

Vol. 1, No. 10, Oktober 2021

\title{
PENGARUH KUALITAS LAYANAN DAN HARGA TERHADAP KEPUASAN KONSUMEN PHOTO STUDIO
}

\author{
Eriek Nurmansyah R, Sitti Hasbiah, Anwar \\ Universitas Negeri Makassar, Indonesia \\ Email: ericknurmansyah80@gmail.com
}

\begin{abstract}
Abstrak
Photo Studio Faramita sendiri merupakan Photo Studio yang berdiri sejak tahun 2017 dan masih aktif di dunia fotografi yang terletak di Kecamatan Campalagian Kabupaten Polewali Mandar. Dalam proses perjalanannya, layanan Faramita Photo Studio selalu memastikan kualitas pelayanan yang maksimal kepada setiap pelanggan. Penelitian ini bertujuan untuk mengetahui bagaimana pengaruh kualitas layanan dan harga terhadap kepuasan konsumen. Jumlah sampel yang digunakan sebanyak 50 orang konsumen Photo Studio Faramita. Pengumpulan data dilakukan melalui observasi dan survei angket. Teknik analisis data yang digunakan adalah analisis regresi linier berganda dengan menggunakan Statistical Products and Service Solutions (SPSS). Hasil penelitian ini menunjukkan bahwa kualitas pelayanan dan harga berpengaruh positif dan signifikan terhadap kepuasan pelanggan. Serta secara simultan kedua variabel bebas tersebut memberikan pengaruh yang signifikan terhadap kepuasan konsumen. Artinya bahwa kualitas layanan dan harga merupakan faktor yang strategis dalam meningkatkan kepuasan konsumen. Ada pengaruh yang signifikan harga terhadap kepuasan pelanggan. Harga memiliki nilai koefisien 2,497, dengan nilai signifikan sebesar 0,016 > 0,05 maka dapat disimpulkan harga berpengaruh terhadap kepuasan pelanggan
\end{abstract}

Kata Kunci: Harga; Kualitas Pelayanan; Kepuasan Konsumen

Diterima: 21-09-2021 Direvisi: 15-10-2021 Disetujui: 18-10-2021

\section{Pendahuluan}

Penelitian ini membahas tentang variabel kualitas pelayanan dan harga terhadap kepuasan konsumen Photo Studio Faramita Di Kecamatan Campalagian Kabupaten Polewali Mandar. Photo Studio Faramita sendiri merupakan Photo Studio yang berdiri sejak tahun 2017 dan masih aktif di dunia fotografi yang terletak di Kecamatan Campalagian Kabupaten Polewali Mandar. Dalam proses perjalanannya, layanan Faramita Photo Studio selalu memastikan kualitas pelayanan yang maksimal kepada setiap pelanggan yang masuk, dan harga yang ditawarkan sesuai dengan hasil yang diperoleh pelanggan. Walaupun terdapat banyak perusahaan Photo Studio di Kabupaten Polewali Mandar, namun dapat dikatakan bahwa hasil foto di Foto Studio Faramita 
berbeda dengan studio foto lainnya, perbedaannya dapat dilihat dari konsep latar belakang yang digunakan dan yang paling membedakan adalah jenisnya. foto bayi atau balita anda baru saja diambil oleh beberapa studio foto lain di area yang sama dan baru-baru ini sangat populer di kalangan masyarakat setempat (Amalia, 2016).

Perjalanan Photo studio Faramita di tahun 2017 sendiri mengalami kenaikan pengguna jasa yang cukup signifikan sampai tahun 2018 dan mengalami penurunan di tahun 2019 kenaikan tersebut dapat dilihat pada tabel berikut:

Tabel i. Data Pengguna Jasa Photo Studio Faramita Dari Tahun 2017 -2019

\begin{tabular}{ccc}
\hline No & Tahun & Layanan Jasa \\
\hline 1 & 2017 & 1.312 \\
\hline 2 & 2018 & 1.825 \\
\hline 3 & 2019 & 1.480 \\
\hline
\end{tabular}

Penurunan angka pengguna jasa di tahun 2019 itu tidak lepas dari keluhan konsumen pada studio Foto Faramita oleh karena itu keluhan dari konsumen harus lebih diperhatikan serta lebih peka terhadap kualitas layanan yang diberikan kepada konsumen. Berikut adalah tabel keluhan konsumen Photo Studio Faramita:

Tabel ii. Keluhan Konsumen Studio Photo Faramita

\begin{tabular}{ccc}
\hline No & Keluhan Konsumen & Jumlah \\
\hline 1 & Kebersihan lingkungan sekitar & 3 \\
\hline 2 & Lama antrian & 16 \\
\hline 3 & Fasilitas ruang tunggu yang kurang memadai & 2 \\
\hline 4 & Pelayanan terhadap konsumen memerlukan waktu & 8 \\
& cukup lama & 5 \\
\hline 5 & Tempat parkir yang kurang luas & 34 \\
\hline
\end{tabular}

Dilihat dari jenis keluhan konsumen seperti kebersihan lingkungan merupakan keluhan terhadap kualitas pelayanan dari segi kehandalan, sedangkan keluhan berupa ruang tunggu dan tempat parkir yang luas termasuk dalam dimensi barang, dan antrian yang panjang. dan jasa lama termasuk dalam dimensi barang. dimensi ketanggapan (Aryani \& Rosinta, 2011).

Selain kualitas pelayanan, harga juga mempengaruhi kepuasan konsumen terhadap pelayanan yang ditawarkan oleh faramita studio, dan harga yang ditetapkan oleh pemilik studio foto tersebut sebenarnya merupakan keunggulan dibandingkan kompetitor yang cukup mahal seperti Tirza Photo Studio dan D'Nos. Studio foto yang merupakan salah satu studio foto terbesar di Polewali Mandar. Berikut perbandingan harga 3 Photo Studio di Polewali Mandar. 
Tabel iii. Daftar Harga 3 Photo Studio di Kabupaten Polewali Mandar

\begin{tabular}{|c|c|c|c|}
\hline \multirow{2}{*}{ Paket } & $\begin{array}{l}\text { Photo Studio } \\
\text { Faramita }\end{array}$ & $\begin{array}{c}\text { Photo Studilo } \\
\text { Tirza }\end{array}$ & $\begin{array}{l}\text { Photo Studio } \\
\text { DNoss }\end{array}$ \\
\hline & Harga & Harga & Harga \\
\hline Paket Reguler 1 & 1- 4 ( $20 \mathrm{Rb} /$ Orang ) & 1-4 ( $25 \mathrm{Rb} /$ Orang ) & $1-2$ ( $25 \mathrm{Rb} /$ Orang ) \\
\hline Paket Reguler 2 & 5 - Up ( $15 \mathrm{Rb} /$ Orang ) & 5 - Up (15 Rb / Orang ) & 3- Up ( $15 \mathrm{Rb} /$ Orang ) \\
\hline Paket Family & $25 \mathrm{Rb} /$ Orang & $25 \mathrm{Rb} /$ Orang & $35 \mathrm{Rb} /$ Orang \\
\hline Paket Praweding & Rp.600.000 & Rp. 1.000 .000 & Rp. 1.500 .000 \\
\hline Paket Wisuda & Rp. 700.000 & Rp.750.000 & Rp.850.000 \\
\hline Paket New Born & Rp.1.000.000 & Rp. 1.500 .000 & - \\
\hline
\end{tabular}

Sumber: Photo Studio Faramita 2020

Sedangkan variabel dari dimensi Tangible dan Assurance secara parsial berpengaruh negatif terhadap kepuasan konsumen. Dan penelitian Agung (2018) menunjukkan bahwa harga tidak berpengaruh positif dan signifikan secara parsial terhadap kepuasan konsumen.

Menurut Kotler dan Keller, kualitas pelayanan adalah segala bentuk kegiatan yang dilakukan perusahaan untuk memenuhi harapan pelanggan. Kualitas pelayanan juga dapat diartikan sebagai upaya untuk memenuhi kebutuhan dan keinginan konsumen serta menyeimbangkan ketepatan penyampaian yang diharapkan oleh konsumen (Kotler \& Keller, 2009). Dapat dikatakan bahwa kualitas pelayanan merupakan kesenjangan antara kenyataan dengan harapan pelanggan atas pelayanan yang diterima. Berdasarkan pengertian di atas, dapat disimpulkan bahwa kualitas pelayanan adalah segala bentuk kegiatan yang dilakukan suatu perusahaan untuk memenuhi harapan pelanggan.

Menurut Lusia, harga adalah jumlah yang dibebankan untuk produk atau layanan, atau jumlah nilai yang ditukarkan pelanggan untuk keuntungan memiliki atau menggunakan produk atau layanan. Berdasarkan definisi tersebut ditegaskan bahwa harga merupakan faktor penting bagi perusahaan, karena harga akan mendatangkan pendapatan bagi perusahaan dan mendorong perkembangan perusahaan yang berkelanjutan. Selain itu, harga juga merupakan alat yang akan melayani pelanggan sebagai proses pertukaran barang atau jasa (Lusia, Suciati, \& Setiowati, 2016).

Sedangkan menurut Hapsar, kepuasan konsumen adalah sejenis reaksi atau kesenangan yang dirasakan konsumen setelah membandingkan hasil atau hasil yang diperoleh konsumen dengan harapan konsumen. Secara umum, harapan konsumen adalah persepsi konsumen terhadap apa yang telah diperolehnya dan produknya (Hapsari, 2011).

\section{Metode Penelitian}

Variabel terikat adalah variabel yang perubahan dan pergerakannya tergantung pada perubahan atau pergerakan variabel lain. Variabel yang terkait dalam penelitian ini adalah kualitas pelayanan dan harga. Variabel bebas adalah variabel yang diduga dapat menyebabkan perubahan atau pergeseran variabel terikat. Variabel bebas dalam 
penelitian ini adalah kepuasan konsumen. Populasi adalah wilayah generalisasi yang terdiri dari objek atau entitas penelitian yang memiliki ciri dan ciri tertentu yang ditentukan oleh peneliti, diteliti dan ditarik kesimpulannya. Penelitian ini menggunakan populasi seluruh pengguna jasa studio foto Faramita tahun 2019, yaitu sebanyak 1.480 konsumen (Tamonsang, 2018).

Sampel adalah bagian dari banyak karakteristik yang dimiliki oleh populasi. Dapatkan informasi dari setiap anggota populasi. Sampel dalam penelitian ini adalah pelanggan yang menggunakan jasa Photo Studio Faramita, dan sebanyak 50 sampel pelanggan yang menggunakan jasa photo Studio Faramita. Hal ini dilakukan dengan hatihati, karena telah ditemukan bahwa skala tersebut konsisten dengan teknik analisis yang digunakan dan efektif mewakili ukuran populasi, dan penentuan ini didasarkan pada pendapat Roscoe (1975), mengutip pendapat Uma Sekaran (2006), yang bertujuan untuk menentukan besarnya populasi. Sampel dengan ukuran sampel lebih besar dari 30 dan kurang dari 500 dianggap mewakili populasi (Hurriyati \& Sofyani, 2010).

Uji reliabilitas adalah alat untuk mengukur kuesioner, yang merupakan variabel atau indikator struktural. Jika jawaban seseorang terhadap suatu pernyataan konsisten atau stabil, maka kuesioner tersebut dikatakan reliabel atau reliabel. Kuesioner disebarkan untuk mengukur reliabilitas pertanyaan satu kali kepada responden, kemudian dengan bantuan program komputer SPSS digunakan fasilitas Cronbach Alpha untuk mengukur korelasi antara skor jawaban atas pertanyaan yang sama. Jika alat penelitian memiliki nilai Cronbach Alpha maka alat penelitian dianggap reliabel > 0,06. Jika nilainya kurang dari 0,60, kuesioner tidak reliabel (Soegoto, 2013).

\section{A. Hasil Penelitian}

Berdasarkan hasil pengolahan data tabel di atas, nilai $r$ hitung lebih besar dari nilai r tabel 0,279, dan dapat disimpulkan bahwa semua item kalimat pada variabel di atas dinyatakan valid dan dapat digunakan untuk pengujian selanjutnya.

Hasil uji reliabilitas menunjukkan bahwa koefisien Cronbach Alpha $(\alpha)$ semua variabel dalam penelitian ini besar yaitu 0,60. Dapat dikatakan bahwa konsep pengukuran masing-masing variabel dalam kuesioner reliabel artinya kuesioner yang digunakan dalam penelitian ini. adalah Penelitian adalah kuesioner yang baik.

\section{a. Uji asumsi klasik}


b. Uji Normalitas

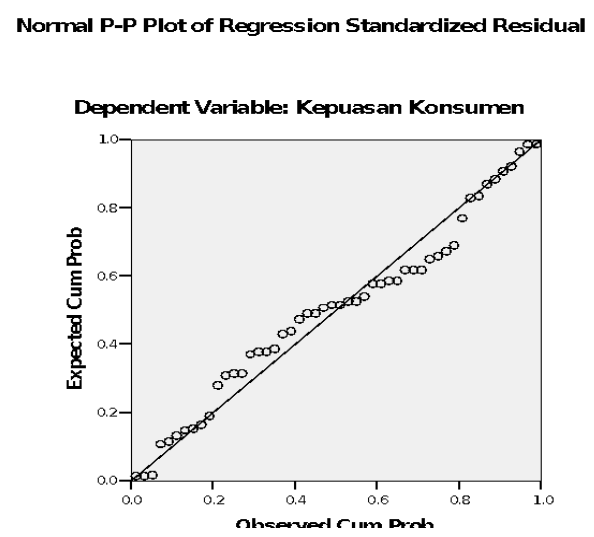

Gambar i. Uji Normalitas

Berdasarkan grafik Scatterplot pada gambar di atas terlihat titik-titik menyebar secara acak (random) baik di atas maupun di bawah angka 0 pada sumbu Y. Maka hal ini dapat disimpulkan bahwa tidak terjadi heteroskedastisitas pada model regresi.

c. Uji Multikolinearitas

Berdasarkan tabel output Coefficients diketahui bahwa nilai tolerance untuk variabel di atas adalah lebih besar dari 0,01. Sementara nilai VIFnya lebih kecil dari 10,00. Maka mengacu pada dasar pengambilan keputusan dalam uji multikolinearitas dapat disimpulkan bahwa tidak terjadi gejala multikolinearitas/bebas multikolinearitas dalam model regresi.

Tabel iv. Hasil Uji Multikolinearitas

Coefficients

\begin{tabular}{llll}
\hline Model & \multicolumn{3}{l}{ Collinearity Statistics } \\
\cline { 2 - 3 } & Tolerance & VIF \\
\hline 1 (Constant) & & \\
\hline & & .679 & 1.473 \\
$\mathrm{X} 1$ & .679 & 1.473 \\
\hline $\mathrm{X} 2$ & & .679 & \\
\hline
\end{tabular}

a. Dependent Variable: Y

Sumber: data primer yang diolah 2020

\section{Analisis Regresi Berganda}

Tabel v. Hasil Uji Regresi Berganda

\begin{tabular}{llllll}
\hline Model & Unstandardized & $\begin{array}{l}\text { Standardize } \\
\mathrm{d}\end{array}$ & $\mathrm{t}$ & Sig. & Collinearity \\
& Coefficients & & & \\
& Coefficient & & Statistics \\
\hline
\end{tabular}




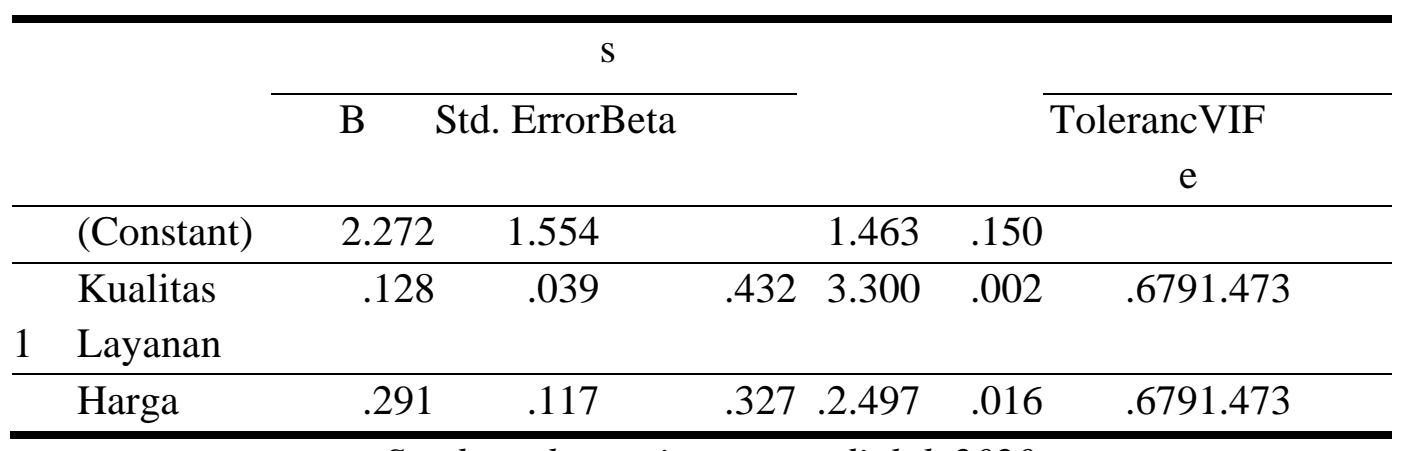

Sumber: data primer yang diolah 2020

Berdasarkan tabel diatas hasil analisis regresi maka diperoleh persamaan regresi berganda sebagai berikut:

$$
\mathrm{Y}=2,272+0,128 \mathrm{X} 1+0,291 \mathrm{X} 2+\mathrm{e}
$$

Persamaan regresi linear berganda di atas dapat diuraikan sebagai berikut:

a. Nilai konstanta sebesar 2,272 bernilai positif artinya besaran kepuasan konsumen tanpa mempertimbangkan dalam hal ini Kualitas Layanan (X1) dan variabel harga (X2) maka nilainya positif sebesar 2,272 maka nilai kepuasan konsumen tetap baik tanpa dipengaruhi oleh kualitas layanan dan harga.

b. Nilai koefisiensi regresi X1 sebesar 0,128 menyatakan bahwa setiap kenaikan 1 satuan dari nilai X1 (Kualitas Layanan) akan mengakibatkan peningkatan Kepuasan Konsumen sebesar 0,128. Artinya jika kualitas layanan ditingkatkan maka kepuasan konsumen akan meningkat secara signifikan.

c. Nilai koefisiensi regresi X2 sebesar 0,291 menyatakan bahwa setiap kenaikan 1 satuan dari nilai X2 (Harga) akan mengakibatkan meningkatkan Kepuasan Konsumen sebesar 0,291 satuan, artinya bahwa jika harga dipersepsikan semakin bersaing maka akan semakin meningkatkan kepuasan konsumen secara signifikan

\section{Uji Hipotesis}

\section{a. Uji parsial (Uji t)}

Uji-t digunakan untuk mengetahui sejauh mana pengaruh variabel bebas terhadap variabel terikat. Syarat diterimanya hipotesis apabila nilai $-\mathrm{t}$ hitung $<-\mathrm{t}$ tabel atau thitung $>\mathrm{t}$ tabel dengan taraf signifikan $<0,05$. Dengan menggunakan sampel sebanyak 50 orang konsumen dengan $\mathrm{df}=\mathrm{n}-\mathrm{k}-1$ atau $\mathrm{df}=50-2-1=47$ maka, diperoleh t-tabel sebesar 2,012 dengan tingkat signifikansinya $(\alpha) 0,05$.

Table vi. Uji parsial (Uji t)

\begin{tabular}{|c|c|c|c|c|c|c|}
\hline \multirow[t]{2}{*}{ Model } & $\begin{array}{l}\text { Unstand } \\
\text { Coeffic }\end{array}$ & $\begin{array}{l}\text { ardized } \\
\text { cients }\end{array}$ & $\begin{array}{l}\text { Standardized } \\
\text { Coefficients }\end{array}$ & \multirow{2}{*}{\multicolumn{2}{|c|}{$\mathrm{t} \quad$ Sig. }} & \multirow{2}{*}{$\begin{array}{l}\text { Collinearity } \\
\text { Statistics } \\
\text { ToleranceVIF }\end{array}$} \\
\hline & $\mathrm{B}$ & \multicolumn{2}{|c|}{ Std. ErrorBeta } & & & \\
\hline (Constant) & 2.272 & \multicolumn{2}{|c|}{1.554} & 1.463 & & 50 \\
\hline
\end{tabular}




\begin{tabular}{llllllll}
\hline & $\begin{array}{l}\text { Kualitas } \\
\text { Layanan }\end{array}$ & .128 & .039 & .432 & 3.300 & .002 & .6791 .473 \\
\hline Harga & .291 & .117 & .327 & .2 .497 & .016 & .6791 .473 \\
\hline
\end{tabular}

Sumber: Data Olahan SPSS tahun 2020

1) Pengujian kualitas layanan terhadap keputusan pembelian

Dari tabel diatas menunjukkan bahwa t hitung $(3,300)>\mathrm{t}$ tabel $(2,012)$ dengan taraf signifikansi 0,002 <0,05. Maka H0 ditolak dan hipotesis yang diterima adalah H1 yang berarti Kualitas Layanan memberikan pengaruh yang signifikan terhadap terhadap Kepuasan Konsumen.

2) Pengujian harga terhadap keputusan pembelian

Dari tabel diatas menunjukkan bahwa t hitung $(2,497)>\mathrm{t}$ tabel $(2,012)$ dengan taraf signifikansi 0,016>0,05. Maka $\mathrm{H} 2$ ditolak dan hipotesis yang diterima adalah $\mathrm{HO}$ yang berarti harga berpengaruh signifikan terhadap Kepuasan Konsumen.

Tabel vii. Hasil Uji F

ANOVA ${ }^{\mathrm{a}}$

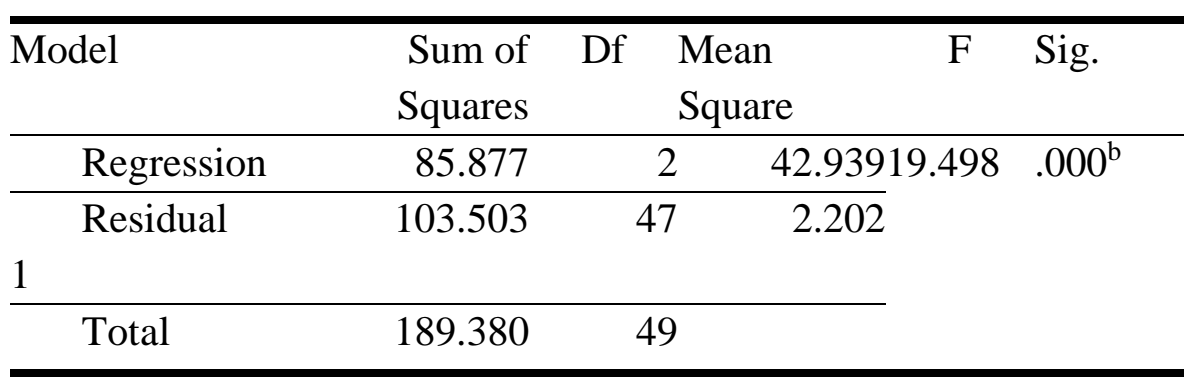

a. Dependent Variable: Kepuasan Konsumen

b. Predictors: (Constant), Harga, Kualitas Layanan

Sumber: data primer yang diolah 2020

Dari tabel di atas menunjukkan bahwa nilai F hitung $(19.498)>\mathrm{F}$ tabel $(3,18)$ dengan taraf signifikansi $0,000<0,05$, yang berarti $\mathrm{H} 0$ ditolak dan $\mathrm{H} 3$ diterima yaitu Variabel Kualitas Layanan (X1), dan Harga (X2) secara simultan berpengaruh signifikan terhadap Kepuasan Konsumen (Y).

\section{B. Pembahasan Penelitian}

Berdasarkan hasil penelitian ini diketahui bahwa kualitas pelayanan dan harga berpengaruh positif dan signifikan terhadap kepuasan pelanggan pengguna jasa Photo Studio Faramita Responden dalam penelitian ini adalah pelanggan pengguna jasa Photo Studio. Studio Faramita memberikan pelayanan pada sampel sebanyak 50 responden yang terbagi menjadi 2 karakteristik yaitu karakteristik berdasarkan jenis kelamin dan usia. 
Menurut Parasuraman, kualitas pelayanan merupakan cerminan pandangan konsumen terhadap pelayanan yang diterima pada waktu tertentu. Kualitas layanan ditentukan oleh pentingnya dimensi layanan. Parasuraman menuturkan jika daftar dimensi utama yang menjadi penentu utama kualitas layanan, antara bukti fisik, keandalan dan reaktivitas. Jika pelayanan yang diterima memenuhi harapan, maka kualitas pelayanan dianggap baik dan memuaskan. Jika pelayanan yang diterima melebihi harapan pelanggan, maka kualitas pelayanan dianggap ideal. Sebaliknya jika pelayanan yang diterima lebih rendah dari yang diharapkan, maka kualitas pelayanan dianggap buruk (Parasuraman, 1988).

Berdasarkan analisis data dalam penelitian ini dapat diketahui bahwa variabel kualitas pelayanan berpengaruh positif dan signifikan terhadap kepuasan pelanggan. Dari perspektif dimensi kualitas layanan seperti bukti fisik, daya tanggap, dan kredibilitas diyakini memiliki kemampuan yang kuat untuk memberikan dampak yang signifikan. Maka untuk pernyataan bahwa "Variabel kualitas pelayanan diduga secara parsial berpengaruh positif dan signifikan terhadap kepuasan konsumen jasa pada Photo Studio Faramita", hal ini sesuai dengan penelitian Lina Sari Situmeang (2017), yaitu faktor kualitas pengolahan berpengaruh positif dan signifikan terhadap kepuasan konsumen. Hal ini menunjukkan bahwa pelayanan yang baik akan memuaskan konsumen. Begitu konsumen puas dengan pelayanan yang diterimanya, mereka akan membandingkan pelayanan yang diberikan. Jika konsumen benar-benar puas, mereka akan menggunakan kembali layanan tersebut dan merekomendasikan layanan Faramita Photo Studio kepada orang lain (Pelealu, Mandey, \& Jorie, 2016).

Menurut hasil penelitian ini, kualitas layanan Photo Studio Faramita tergolong tinggi dalam hal bukti fisik, keandalan dan daya tanggap. 11 pertanyaan yang terdapat dalam kuesioner penelitian membuktikan hal ini, dan hampir semua responden setuju dengan rentang skor tinggi. Dibandingkan dengan kompetitor, pernyataan Faramita Studio dalam memberikan informasi mengenai jadwal pemotretan sudah benar. Ini adalah indikator yang benar untuk skor tertinggi, artinya Faramita Photo Studio dapat mengatasi konsumsi pada saat pengambilan gambar. Keluhan penulis seringkali melibatkan banyak keluhan, seperti jadwal yang padat, sehingga sering terjadi antrian Panjang. Photo Studio Faramita bisa merespon dengan cepat hal ini. Meskipun skor terendah adalah pernyataan tentang perlengkapan dan kenyamanan lounge, namun hal ini berarti bahwa staf Photo Studio Faramita belum dapat memberikan kenyamanan bagi seluruh konsumen, meskipun skor untuk pernyataan tersebut masih sangat tinggi. Kisaran tingkat hasil.

Berdasarkan hasil penelitian yang diperoleh, variabel harga juga berpengaruh positif signifikan terhadap kepuasan konsumen. Hal ini disebabkan hasil uji t yaitu nilai t hitung harga variabel lebih besar dari nilai t tabel, dan nilai sig yang diperoleh lebih rendah dari tingkat signifikansi penelitian yaitu variabel harga berpengaruh positif dan signifikan terhadap kepuasan pengguna jasa Faramita Studio terhadap konsumen. Dengan demikian, "bagian variabel harga berpengaruh positif dan signifikan terhadap kepuasan konsumen jasa Photo Studio Faramita" dapat diterima, hal ini sesuai dengan penelitian (Lina Sari Situmeang, 2017), dimana bagian faktor harga berpengaruh positif dan positif. 
pada kepuasan konsumen. Hal ini menunjukkan bahwa ekspektasi harga lebih sesuai, dan berbanding lurus dengan kualitas pelayanan, sehingga konsumen merasa puas, karena dengan naiknya harga maka kualitas yang terjamin akan meningkat untuk menjamin kepuasan pelanggan.

Variabel harga Faramita Photography Studio dievaluasi dari segi kepastian harga dan daya saing harga. Dikonfirmasi dari empat pertanyaan dalam survei, hampir semua responden memutuskan sangat setuju dengan kisaran poin sangat baik. Diantaranya, pernyataan bahwa Faramita Photo Studio lebih murah dari Photo Studios lainnya mendapat skor tertinggi, yang berarti bahwa Faramita Photo Studio dapat memenuhi kebutuhan konsumen dan dapat menyesuaikan dengan pendapatan konsumen di wilayah tersebut. Pada saat yang sama, pernyataan apakah harga memadai dan harapan kualitas "mendapatkan peringkat terendah, yang berarti bahwa karyawan Photo Studio Faramita tidak akan menunjukkan kepada pelanggan kualitas tertinggi dari foto yang dikirim ke pelanggan, bahkan jika peringkat dari pernyataan ini masih merupakan serangkaian hasil yang baik.

Berdasarkan hasil penelitian yang diperoleh, kualitas pelayanan dan harga berpengaruh positif dan signifikan terhadap variabel kepuasan konsumen pengguna jasa Faramita Photo Studio. Berdasarkan hasil uji koefisien determinasi, kualitas pelayanan dan harga memiliki kontribusi yang tinggi terhadap kepuasan pelanggan yang menggunakan jasa Faramita Photo Studio. Besarnya dampak ini baik, namun perlu ditambahkan variabel lain untuk mengukur kepuasan pelanggan, karena selain kualitas pelayanan dan harga, masih banyak faktor lain yang juga mempengaruhi kepuasan pelanggan. Misalnya, meskipun kualitas pelayanan dan harga bagus, kualitas produk tidak memuaskan dan kepuasan pelanggan akan menurun. Untuk mendapatkan kepuasan pelanggan yang maksimal, kita perlu memahami faktor-faktor yang mempengaruhi kepuasan pelanggan. Ketika faktor-faktor yang mempengaruhi berinteraksi secara harmonis dan positif, kepuasan konsumen akan meningkat.

\section{Kesimpulan}

Ada pengaruh yang signifikan kualitas pelayanan terhadap kepuasan pelanggan. Kualitas pelayanan memiliki nilai koefisien 3,300, dengan nilai signifikan sebesar 0,002 $<0,005$ maka dapat disimpulkan kualitas pelayanan berpengaruh terhadap kepuasan pelanggan. Ada pengaruh yang signifikan harga terhadap kepuasan pelanggan. Harga memiliki nilai koefisien 2,497, dengan nilai signifikan sebesar 0,016 >0,05 maka dapat disimpulkan harga berpengaruh terhadap kepuasan pelanggan.

Secara simultan, variabel kualitas pelayanan dan harga berpengaruh secara signifikan terhadap kepuasan pelanggan. Hal ini dapat ditunjukan dengan signifikan secara simultan sebesar 0,000 yang lebih kecil dari tingkat kesalahan yang ditentukan yaitu $5 \%$ yaitu 0,05 yang berarti $\mathrm{H} 3$ diterima. 


\section{BIBLIOGRAFI}

Amalia, Aisyah. (2016). Perencanaan strategi pemasaran dengan pendekatan bauran pemasaran dan SWOT pada perusahaan POPSY TUBBY. Jurnal Manajemen Dan Start-Up Bisnis, 1(3), 297-306. Google Scholar.

Aryani, Dwi, \& Rosinta, Febrina. (2011). Pengaruh kualitas layanan terhadap kepuasan pelanggan dalam membentuk loyalitas pelanggan. BISNIS \& BIROKRASI: Jurnal Ilmu Administrasi Dan Organisasi, 17(2). Google Scholar.

Hapsari, Respati Mengayu. (2011). Pengaruh Kualitas Pelayanan, Fasilitas Fisik Dan Promosi Terhadap Kepuasan Konsumen Pada Hotel Semesta Semarang. Universitas Negeri Semarang. Google Scholar

Hurriyati, Ratih, \& Sofyani, Santi. (2010). Pengaruh Corporate Social Responsibility Terhadap Corporate Image PT Bank Negara Indonesia, Tbk. Strategic: Jurnal Pendidikan Manajemen Bisnis, 10(1), 63-75. Google Scholar

Kotler, Philip, \& Keller, Kevin Lane. (2009). Manajemen Pemasaran, Edisi 13. Jakarta: Erlangga, 14. Google Scholar.

Lusia, Amelita, Suciati, Pijar, \& Setiowati, Endang. (2016). Motivasi Intrinsik Yang Mempengaruhi Pemilihan Jurusan Dan Universitas (Studi Pada Mahasiswa Baru Program Vokasi Universitas Indonesia Angkatan 2015). Jurnal Vokasi Indonesia, 3(2) Google Scholar.

Marathi, N. C. (2016). Pengaruh Kualitas Layanan Dan Harga Terhadap Kepuasan Pelanggan Jasa Transportasi Ojek Online (Studi Pada Konsumen Gojek Di Surabaya). 1-12. Google Scholar.

Nurjanah, R., \& Mulazid, A. S. (2018). Pengaruh Kualitas Pelayanan Dan Corporate Social Responsibility Terhadap Citra Perusahaan. 9(1), 40-53. Google Scholar.

Oktarini, R. (2019). Pengaruh Kualitas Pelayanan Dan Harga Terhadap Kepuasan Pelanggan Pengguna Jasa Aplikasi Gojek Di Kota Tangerang. 6(2), 248-257.e Google Scholar.

Pelealu, Vionita Rosaliana, Mandey, Silvya, \& Jorie, Rotinsulu Jopie. (2016). Analisis Strategi Promosi dan Kualitas Pelayanan Terhadap Kepuasan Pengguna Car Care Center (C3) Car Wash Manado. Jurnal EMBA: Jurnal Riset Ekonomi, Manajemen, Bisnis Dan Akuntansi, 4(2). Google Scholar.

Soegoto, Agus Supandi. (2013). Persepsi nilai dan kepercayaan terhadap kepuasan dan dampaknya terhadap loyalitas konsumen. Jurnal EMBA: Jurnal Riset Ekonomi, Manajemen, Bisnis Dan Akuntansi, 1(3). Google Scholar.

Tamonsang, Matheous. (2018). Pengaruh Bauran Pemasaran, Kelompok Referensi, 
Pengaruh Kualitas Layanan Dan Harga Terhadap Kepuasan Konsumen Photo Studio

Keluarga, Peran dan Status Terhadap Keputusan Penggunaan Kartu Kredit (Studi Pada Anggota IDI Malang). Equilibrium: Jurnal Ekonomi-Manajemen-Akuntansi, 14(2), 93-100. Google Scholar. 